\title{
HISTOPATHOLOGICAL EVALUATION OF NEOPLASTIC AND NON-NEOPLASTIC BONE TUMOURS IN A TEACHING HOSPITAL
}

\author{
Saadvi Kethireddy1, K. Raghu², K. P. A. Chandra Sekhar', Y. Srikanth Babu', Monalisa Dash ${ }^{5}$ \\ ${ }_{1}^{1}$ Postgraduate, Department of Pathology, SVS Medical College, Telangana. \\ 2 Professor, Department of Pathology, SVS Medical College, Telangana. \\ 3 Professor, Department of Pathology, SVS Medical College, Telangana. \\ 4 Professor, Department of Pathology, SVS Medical College, Telangana. \\ 5 Postgraduate, Department of Pathology, SVS Medical College, Telangana.
}

\begin{abstract}
\section{BACKGROUND}

Bone tumours are comparatively uncommon among wide array of lesions and pose a diagnostic problem. Definitive clinical diagnosis of bone lesion is often difficult. So it is essential to identify the lesion correctly before deciding the line of treatment. For the correct diagnosis of bone lesions, charting out treatment plan and estimating prognosis, interpretation of biopsy material proves to be indispensable.

Aim of the study is to study histopathological features of bone lesions and their correlation with age of presentation, site and type of lesion.
\end{abstract}

\section{MATERIALS AND METHODS}

The duration of the study was 2 years [June 2014-May 2016]. A review of histopathological reports of all bone specimens received in the Department of Pathology, SVS Medical College over a period of 2 years was done. A total of 46 bone lesions were analysed. Bone biopsy was performed by either percutaneous method with needle/drill or open surgical biopsy. If attached soft tissue was also received, bony tissues were put for decalcification (10\% nitric acid). Soft tissue was immediately fixed into $10 \%$ forma lin and processed by paraffin embedding. Sections were stained by haematoxylin and eosin stain and microscopic examination was done.

\section{RESULTS}

Total non-neoplastic bone lesions were 18 (39.1\%) while that of neoplastic lesions were 28 (60.9\%). Both neoplastic and nonneoplastic lesions were more prevalent in < 20 years age group. Among the non-neoplastic lesions, osteomyelitis lesions (38.9\%) were the commonest while giant cell tumour (42.8\%) was common neoplastic lesions. Overall most common bone involved was femur.

\section{CONCLUSION}

Though bone tumours are less common lesions and pose a diagnostic problem, if viewed in perspective of clinico-radiology and histopathology, a correct diagnosis can be reached.

\section{KEYWORDS}

Bone Tumours, Histopathology, Giant Cell Tumour, Osteosarcoma.

HOW TO CITE THIS ARTICLE: Kethireddy S, Raghu K, Chandra Sekhar KPA, et al. Histopathological evaluation of neoplastic and non-neoplastic bone tumours in a teaching hospital. J. Evolution Med. Dent. Sci. 2016;5(86):6371-6374, DOI: $10.14260 /$ jemds/2016/1441

\begin{abstract}
BACKGROUND
Neoplasms and tumour like conditions of bone are rare. Thus, orthopaedic surgeons, radiologists, and pathologists generally have little experience with these lesions. Bone tumours also tend to affect young children and adolescents. Bone lesions often pose diagnostic challenges to surgical pathologists. Therefore, an integrated approach involving radiographic, histologic, and clinical data are necessary to form an accurate diagnosis and to determine the degree of activity and malignancy of each lesion. A proper histopathological diagnosis is useful in confirming the diagnosis and helps in
\end{abstract}

Financial or Other, Competing Interest: None.

Submission 20-09-2016, Peer Review 13-10-2016,

Acceptance 20-10-2016, Published 26-10-2016.

Corresponding Author:

Dr. Saadvi Kethireddy,

8/38, Bahar, Sahara States,

Mansoorabad, Lb Nagar,

Hyderabad-68, Telangana.

E-mail: saadvi Kethireddy@gmail.com

DOI: $10.14260 /$ jemds $/ 2016 / 1441$

\section{(c) $($ () $\ominus$}

staging the tumour and aid the surgeon in planning limb salvage surgery for early malignant and benign bone lesions.[1] Many inflammatory, neoplastic, degenerative and metabolic diseases occur in bones. They may affect children, adults or the elderly persons. They sometimes occur and develop quickly, often revealing themselves through pain, or the appearance of a palpable mass or by restricting the movement of the part involved. Common presentations are progressive pain, swelling, tenderness and in some cases, acute pathological fracture.[2,3]

Clinical symptoms alone are of relatively little significance in most bone lesions as most patients complain of pain or swelling or both. Such as patient with Ewing's sarcoma may present with fever and increased erythrocyte sedimentation rate mimicking the diagnosis of osteomyelitis.[1] The roentgenogram can be considered as gross manifestation of bone lesion. It helps in defining exact location of lesion, but there are also limitations such as some primitive bone lesions. Ewing's sarcoma of bone may appear as normal while some benign lesions like aneurysmal bone cyst or osteoblastoma may appear aggressive on roentgenogram. Biochemical 
investigations alone are also of not major value in the diagnosis of most of the bone lesions except in some cases as in myeloma.

Histopathological study enables us to understand the spectrum of bone lesions and gives an idea of different bone tumours and tumour-like lesions in population among different age group and sex. Bone lesions often pose diagnostic challenges to surgical pathologists. Therefore, an integrated approach involving radiographic, histologic, and clinical data are necessary to form an accurate diagnosis and to determine the degree of activity and malignancy of each lesion. A proper histopathological diagnosis is useful in confirming the diagnosis and helps in staging the tumour and aid the surgeon in planning limb salvage surgery for early malignant and benign bone lesions.

The present study was carried out to assess the patterns of various bone lesions and their relative frequency among 46 patients whose biopsy specimens were received in the Department of Pathology at SVS Medical College, Mahabubnagar during a period of 2 years (June 2014-May 2016).

\section{MATERIALS AND METHODS}

This study conducted in the Department of Pathology at SVS Medical College, Mahabubnagar covering a period of 2 years from June 2014-May 2016. All the histopathological reports and slides of patients who had bone tissue biopsies were reviewed to provide relevant information on age, sex, histopathological interpretation, and the anatomical site of occurrence. All tumours of hematopoietic and odontogenic origin were excluded in this study.

Bony along with soft tissue biopsy or in some cases amputated limb was received, and thorough gross examination of each lesion was done. Soft tissue of each biopsy was immediately fixed into $10 \%$ formalin and processed by paraffin embedding. Bone from each biopsy was kept for decalcification in $10 \%$ nitric acid. After that, fixation in $10 \%$ formalin, processing, section cutting and haematoxylin and eosin staining was performed.

\section{RESULTS}

A histopathological study of various bone lesions was carried out at a teaching hospital from June 2014 to May 2016. During these 2 years, total 46 cases were studied. Bone lesions were more common in < 20 years age group (43.5\%). Nonneoplastic lesions comprised 18 cases (39.1\%), 25 cases (54.3\%) had benign lesions and malignant lesions accounted for 3 cases (6.52\%). Males (25 out of 46 cases, $54.3 \%$ ) were affected more commonly than females (21 out of 46 cases, $45.7 \%$ ) with male to female ratio as 1.2:1.

Amongst non-neoplastic lesions, chronic osteomyelitis (7 cases, $38.9 \%$ ) were commonest followed by tuberculous Osteomyelitis ( 4 cases, $22.2 \%$ ) and aneurysmal bone cyst (3 cases, $16.66 \%$ ) while giant cell tumour (12 cases, $42.8 \%$ ) was more common in the category of benign neoplastic lesions. Osteochondromas (6 cases, $21.42 \%$ ) was also reasonably common. Osteoma (3 cases, 10.7\%) and chondroblastoma (2 cases, 7.14\%) were common neoplastic bone lesions. Among malignant tumours, sarcoma accounts for 3 cases (osteosarcoma 2, and Ewing's sarcoma 1).

\begin{tabular}{|c|c|c|c|c|}
\hline \multirow{2}{*}{$\begin{array}{c}\text { Bone } \\
\text { lesions }\end{array}$} & \multirow{2}{*}{$\begin{array}{c}\text { Non } \\
\text { Neoplastic }\end{array}$} & \multicolumn{2}{|c|}{ Neoplastic } & \multirow{2}{*}{ Total } \\
\cline { 3 - 4 } & Benign & Malignant & \\
\hline Male & 10 & 15 & 3 & 28 \\
\hline Female & 8 & 10 & 0 & 18 \\
\hline Total & $\mathbf{1 8}$ & $\mathbf{2 5}$ & $\mathbf{3}$ & $\mathbf{4 6}$ \\
\hline \multicolumn{2}{|c|}{ Table 1. Gender Distribution of the Lesions of Bone } \\
\hline
\end{tabular}

\begin{tabular}{|c|c|c|c|c|}
\hline \multirow{2}{*}{$\begin{array}{c}\text { Age } \\
\text { (Years) }\end{array}$} & $\begin{array}{c}\text { Non } \\
\text { Neoplastic }\end{array}$ & \multicolumn{2}{|c|}{ Neoplastic } & Total \\
\cline { 3 - 5 } & Benign & Malignant & \\
\hline $21-40$ & 7 & 12 & 1 & 20 \\
\hline $41-60$ & 3 & 9 & 1 & 13 \\
\hline$>60$ & 5 & 3 & 0 & 8 \\
\hline \multicolumn{7}{|c|}{ Table 2. Age wise Distribution of the Bone Lesions } \\
\hline
\end{tabular}

\begin{tabular}{|c|c|c|}
\hline Non Neoplastic & \multicolumn{2}{|c|}{ Neoplastic } \\
\hline & Benign & Malignant \\
\hline Osteomyelitis - 7 & $\begin{array}{c}\text { Giant cell tumour } \\
-12\end{array}$ & $\begin{array}{c}\text { Osteosarcoma } \\
-2\end{array}$ \\
\hline $\begin{array}{c}\text { Tubercular } \\
\text { osteomyelitis - } 4\end{array}$ & $\begin{array}{c}\text { Chondroblastoma } \\
-2 \\
\end{array}$ & $\begin{array}{c}\text { Ewing's } \\
\text { sarcoma - } 1\end{array}$ \\
\hline $\begin{array}{c}\text { Aneurysmal bone } \\
\text { cyst }-3\end{array}$ & Enchondroma - 2 & \\
\hline Simple cyst -1 & Osteoma - 3 & \\
\hline $\begin{array}{c}\text { Fibrous dysplasia } \\
-2 \\
\end{array}$ & $\begin{array}{c}\text { Osteochondroma } \\
-6 \\
\end{array}$ & \\
\hline $\begin{array}{l}\text { Non-ossifying } \\
\text { fibroma - } 1\end{array}$ & & \\
\hline Total $=18$ & Total $=25$ & Total $=3$ \\
\hline
\end{tabular}

\begin{tabular}{|c|c|c|c|}
\hline Location & $\begin{array}{c}\text { Non } \\
\text { Neoplastic }\end{array}$ & Neoplastic & Total \\
\hline Femur & 9 & 16 & 25 \\
\hline Tibia & 4 & 7 & 11 \\
\hline Humerus & 2 & 2 & 4 \\
\hline Radius & 0 & 2 & 2 \\
\hline Ulna & 1 & 1 & 2 \\
\hline Small bones & 2 & 0 & 2 \\
\hline Total & $\mathbf{1 8}$ & $\mathbf{2 8}$ & $\mathbf{4 6}$ \\
\hline Table 4. Distribution of Bone Lesions According to \\
\multicolumn{4}{|c|}{ Location } \\
\hline
\end{tabular}

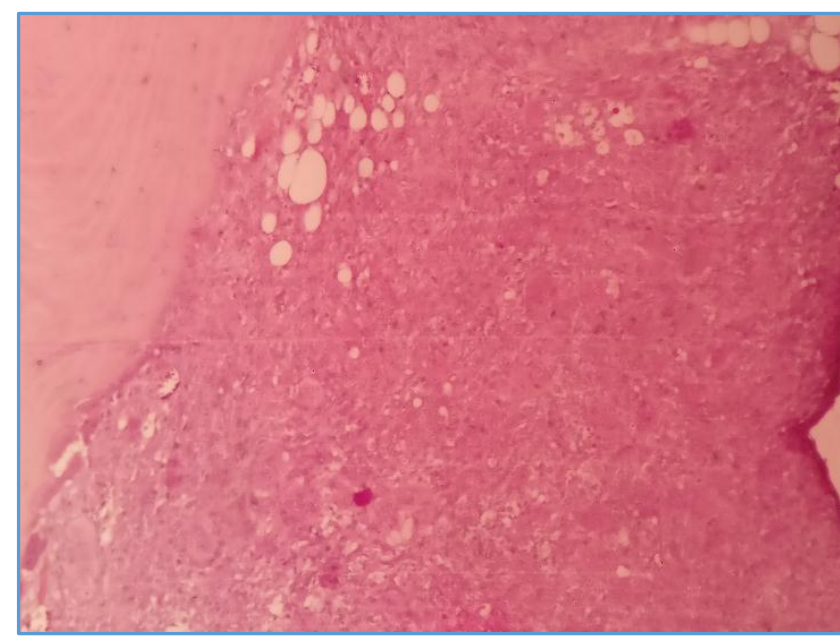

Giant Cell Tumour 


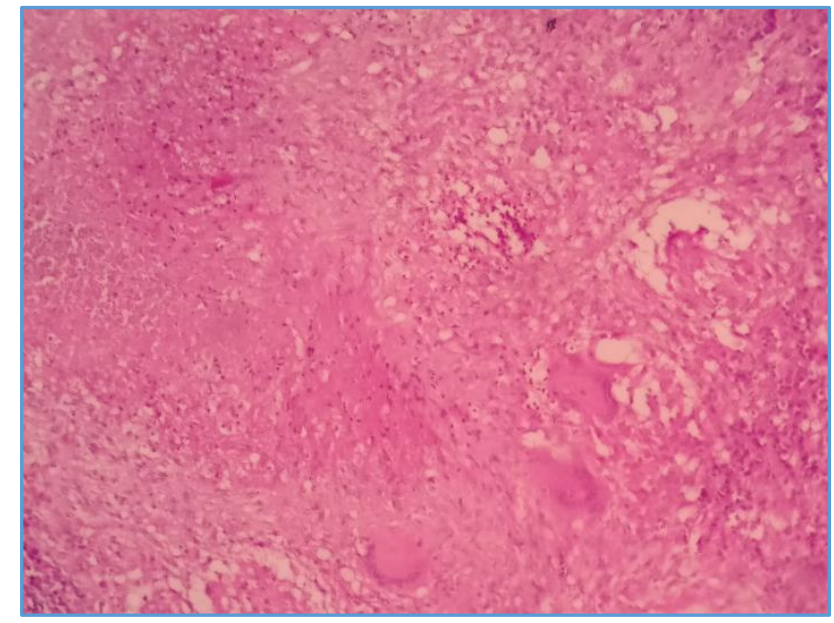

Tuberculous Osteomyelitis

\section{DISCUSSION}

Bone lesions themselves constitute a small fraction of all the lesions prevailing in a population. It is absolutely essential to be equipped with information regarding the clinical details viz. age, gender, site and radiological findings before diagnosis of any bone lesion. Certain entities can be confused clinically like osteomyelitis and Ewing's sarcoma, traumatic fracture or pathological fracture, osteoblastoma and osteosarcoma and tuberculosis or malignancy. Therefore, histological diagnosis is a must in all bone lesions to differentiate above-mentioned entities to confirm the diagnosis of radiologist and clinician and to predict the prognosis of bone lesion on the basis of different cytomorphological criteria. The present study was undertaken with a view to find out incidence of bone neoplastic and non-neoplastic bone conditions in patients presenting to a teaching hospital and to find out common type of lesions and tumours.

In present study, bone lesions were most commonly seen in younger age group ( $<20$ years). Males were more commonly affected. Most tumours of the bone showed male preponderance with male to female ratio of $1.2: 1$. Similar findings were reported in other studies. ${ }^{[4-6]}$ Femur was most common bone (54.34\%) involved. Non-neoplastic and benign lesions were more common than malignant lesions similar to other study.[7] Benign lesions were more common than malignant lesions.[8-13] Neoplastic lesions were found to be more common than non-neoplastic lesions which is in conformity with studies done by Settakom et al[14] Chronic osteomyelitis was most common non-neoplastic condition affecting 7 patients (38.9\%). Other non-neoplastic conditions were tubercular osteomyelitis and ABC.

Benign cases were more common as compared to malignant cases similar to other studies. [8-12] Giant cell tumour was the most common neoplastic benign condition. Femur was commonly affected (54.34\%) similar to other study.[15] Males are affected more than females similar to other study.[11] Other benign tumours were chondroblastoma, enchondroma, osteoma and osteochondroma. Krishnappa et al. 2016[16] reported two cases of chondroblastoma. Rajani et al 2014[17] accounted for 2.3\% and Khabuss et al 2010[18] accounted for one case in their study. Osteosarcoma was the most common malignant lesion in our study.

\section{CONCLUSION}

In our study, neoplastic bone lesions were more common $(60.9 \%)$ than non-neoplastic bone lesions (39.1\%). Bone lesions were more common in younger age group $<20$ years. Males were more commonly affected than females. Chronic osteomyelitis was the most common non-neoplastic lesion, followed by tuberculous osteomyelitis and aneurysmal bone cyst. In case of neoplastic lesions, giant cell tumour was the commonest benign tumour. Amongst malignant lesions, osteosarcoma was the most common malignant tumour in our study. Femur was the most frequently affected location. All the lesions were quite consistent in their occurrence with relation to age, sex and site of distribution.

\section{REFERENCES}

1. Sternberg SS, Millis SE, Carter D. Sternberg diagnostic surgical pathology. $5^{\text {th }}$ edn. Philadelphia: Lippincott Williams \& Wilkins 2010:p. 236.

2. Tang L, Xiangsheng Z, Qing Z, et al. Enlargement of a humeral osteochondroma after skeletal maturity: a case report. J Bone Joint Surg Am 2011;93(6):e20.

3. Rosai J. Bone and joints. In: Rosai and Ackerman's surgical pathology, 10th edn. New Delhi: Elsevier 2012:2013-2104.

4. Baena-Ocampo Ldel C, Ramirez-Perez E, Linares-Gonzalez LM, et al. Epidemiology of bone tumors in Mexico City: retrospective clinicopathologic study of 566 patients at a referral institution. Ann Diagn Pathol 2009;13(1):16-21.

5. Mohammed A, Sani MA, Hezekiah IA, et al. Primary bone tumor and tumor -like lesions in children in Zaria, Nigeria. Afr J Paediatr Surg 2010;7(1):16-8.

6. Sharma S, Mehta NP. Histopathological study of bone tumors. International Journal of Science and Research 2015;4(12):1970-1974.

7. Patel D, Patel P, Gandhi T, et al. Clinicopathological study of bone lesions in tertiary care center-a review of 80 cases. International Journal of Advanced Research 2015; 3(7):1267-1272.

8. Rao VS, Pai MR, Rao RC, et al. Incidence of primary bone tumours and tumour like lesions in and around Dakshina Kannada district of Karnataka. J Indian Med Assoc 1996;94(3):103-4, 121.

9. Solooki S, Vosoughi AR, Masoomi V. Epidemiology of musculoskeletal tumors in Shiraz, south of Iran. Indian J Med Paediatr Oncol 2011;32(4):187-91.

10. Mohammed A, Isa HA. Pattern of primary tumours and tumour-like lesions of bone in Zaria, northern Nigeria: a review of 127 cases. West Afr J Med 2007;26(1):37-41.

11. Obalum DC, Giwa SO, Banjo AF, et al. Primary bone tumours in a tertiary hospital in Nigeria: 25 year review. Niger J Clin Pract 2009;12(2):169-72.

12. Rehman A, Qureshi H, Shafiullah. Bone tumors and tumor-like lesions: 10 years retrospective analysis of biopsy results. J Postgrad Med 2004;18:40-5.

13. Wani LA, Ashai FB, Banday BM, et al. Primary bone tumours in Kashmir valley a retrospective histopathological study. International Journal of Basic and Applied Sciences 2015;4(1):51-56.

14. Settakorn J, Lekawanvijit S, Arpornchayanon O, et al. Spectrum of bone tumors in Chiang Mai University Hospital, Thailand according to WHO Classification 2002: a study of 1, 001 cases. J Med Assoc Thai 2006;89(6):780-7. 
15. Modi D, Rathod GB, Delwadia KN, et al. Histopathological study of bone lesions-A review of 102 cases. IAIM 2016;3(4):27-36.

16. Krishnappa A, Shobha SN, Shankar SV, et al. Fine needle aspiration cytology of chondroblastoma: a report of two cases with brief review of pitfalls. J Cytol 2016;33(1): 40-2.

17. Rajani M, Prasanna RM, Saibala G, et al. Fine needle aspiration cytological study of bone tumors and tumor like lesions with clinic pathological correlation. IOSR J Pharm Biol Sci (IOSR-JPBS) 2014;9(4):130-42.
18. Khalbuss WE, Teot LA, Monaco SE. Diagnostic accuracy and limitations of fine-needle aspiration cytology of bone and soft tissue lesions: a review of 1114 cases with cytological-histological correlation. Cancer Cytopathol 2010;118(1):24-32. 